PROFESIONALES Y HERRAMIENTAS PARA EL DESARROLLO LOCAL Y SUS SINERGIAS TERRITORIALES. EVALUACIÓN Y PROPUESTAS DE FUTURO IX Coloquio Nacional de Desarrollo Local del GTDL-AGE 

ANTONIO MARTÍNEZ PUCHE, XAVIER AMAT MONTESINOS, ISABEL SANCHO CARBONELL y DANIEL SANCHIZ CASTAÑO (EDS.)

\section{PROFESIONALES Y HERRAMIENTAS PARA EL DESARROLLO LOCAL Y SUS SINERGIAS TERRITORIALES. EVALUACIÓN Y PROPUESTAS DE FUTURO}

IX Coloquio Nacional de Desarrollo Local del GTDL-AGE

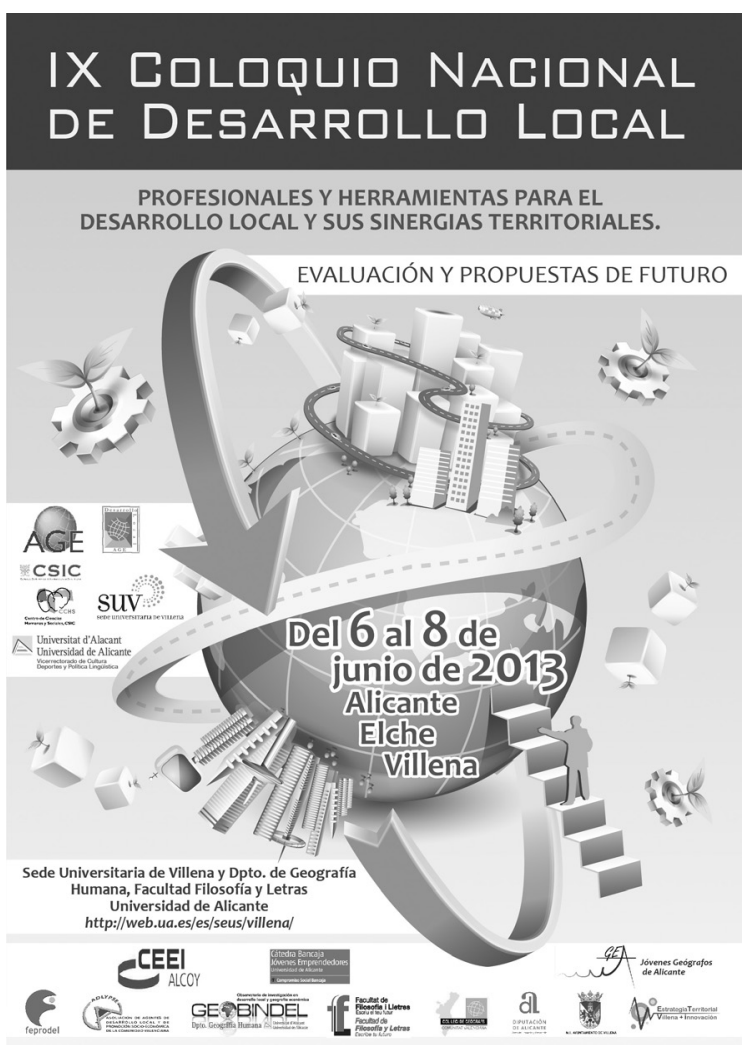


Este libro ha sido examinado y valorado por evaluadores ajenos a la Universidad de Alicante, con el fin de garantizar la calidad científica del mismo.

Publicacions de la Universitat d'Alacant

03690 Sant Vicent del Raspeig

Publicaciones@ua.es

http://publicaciones.ua.es

Telèfon: 965903480

(C) Antonio Martínez Puche, Xavier Amat Montesinos,

Isabel Sancho Carbonell y Daniel Sanchiz Castaño (eds.), 2016

(C) d'aquesta edició: Universitat d'Alacant

ISBN: 978-84-16724-00-0

Dipòsit legal: A 92-2016

Disseny de coberta: candela ink

Composició: Página Maestra (Miguel Ángel Sánchez Hernández)

Impressió i enquadernació: Guada Impresores

\section{unte \\ Unión de Editoriales
Universitarias Españolas \\ WWW.une.es
WWA}

Esta editorial es miembro de la UNE, cosa que garantiza la difusión y comercialización nacional y internacional de sus publicaciones.

Reservados todos los derechos. Cualquier forma de reproducción, distribución, comunicación pública o transformación de esta obra sólo puede ser realizada con la autorización de sus titulares, salvo excepción prevista por la ley. Diríjase a CEDRO (Centro Español de Derechos Repográficos, www.cedro.org) si necesita fotocopias o escanear algún fragmento de esta obra. 


\title{
EL CICLOTURISMO: UN NUEVO PRODUCTO PARA EL DESARROLLOLOCAL Y TURÍSTICO DE LA PROVINCIA DE ALICANTE
}

\author{
Joaquín Palací Soler \\ Crea360 Consultoría de Desarrollo Local \\ joaquin.palaci@geografos.org
}

RESUMEN

Teniendo en cuenta que la provincia de Alicante ha sido paso habitual de la Vuelta ciclista a España y que numerosos equipos ciclistas profesionales realizan sus pretemporadas en este espacio, podemos afirmar que estamos ante un ámbito territorial apto para desarrollar el ciclismo, como elemento para el desarrollo local y turístico de la provincia.

Este modelo turístico basado en el ciclismo experiencial se debe apoyar en la consolidación de una marca territorial que identifique Provincia de Alicante con Ciclismo y viceversa y que sea capaz de englobar a todos aquellos agentes sociales relacionados con el turismo y el desarrollo local.

En este momento de crisis económica es necesario ofrecer nuevos productos turísticos que diversifiquen y fomenten la desestacionalización de la oferta turística de la provincia de Alicante, con el objetivo de que la industria turística continúe siendo un motor para la generación de rentas y empleo en este territorio sin necesidad de consumir territorio, ya que el territorio entendido como paisaje es vital para el desarrollo de esta actividad.

Palabras clave: ciclismo, producto turístico, revitalización, territorio.

THE CYCLING: A NEW PRODUCT FOR LOCAL DEVELOPMENT AND TOURISM IN THE PROVINCE OF ALICANTE

\section{Abstract}

Considering that Alicante has been a customary step of the Tour of Spain and that many professional cycling teams make their preseason in this space, we 
can say that this is a territory suitable for developing cycling as element for local development and tourism in the province.

This turistic model based on experienced cycling must be supported by the consolidation of a territorial marking identifying Alicante Province with Cycling and vice versa and to be able to encompass all those social agents related to tourism and local development.

In this time of economic crisis it is necessary to provide new tourism products to diversify and promote the seasonality of tourism in the province of Alicante, with the aim that the tourism industry continues to be an engine for generating income and employment in that State without consuming territory, as the territory is understood as landscape that is vital for this activity.

Keywords: cicling, tourism product, revitalization, territory.

\section{LA NECESIDAD DE NUEVOS PRODUCTOS TURÍsticos PARA LA PROVINCIA DE AliCANTE}

La creciente segmentación de la demanda turística aconseja el desarrollo de promociones específicas para segmentos concretos. La promoción temática se plantea como una vía necesaria para la diversificación de la oferta turística. De este modo, ofertas dispersas cobran mayor entidad y mejoran el posicionamiento de un espacio turístico en modalidades turísticas específicas.

El espacio turístico de la provincia de Alicante parte de una realidad y de una historia que no puede obviarse o negarse, hay que ser conscientes que el espacio turístico de la provincia de Alicante no se concibe sin la tipología turística del "Sol y Playa". Pero sí pueden llevarse a cabo intervenciones, para diversificar la oferta y conseguir la identificación del territorio con otras actividades o tipologías turísticas. La provincia de Alicante cuenta con argumentos y saber hacer para atraer a perfiles de turistas vinculados con nuevos productos turísticos.

Aunque el turismo de sol y playa seguirá siendo, producto turístico mayoritario en cuanto a grandes cifras, en la actualidad estamos observando el posicionamiento estratégico de distintos productos turísticos en la provincia de Alicante tales como la gastronomía, turismo cultural, turismo de golf, cicloturismo... Son tipologías turísticas que se han de potenciar con el objetivo de prolongar la larga cola del turismo en nuestra provincia. (Plan estratégico global de Turismo de la Comunidad Valenciana, 2010). Sin duda hay que aprovechar la notoriedad que genera el turismo de Sol y playa en la provincia de Alicante para poder posicionar y consolidar nuevos productos turísticos basados en la sostenibilidad ambiental y en la vivencia de experiencias.

El incremento de la competencia obliga a potenciar los elementos de diferenciación y singularidad de la oferta turística, en este caso pretendemos situar al ciclismo, como elemento clave que defina un nuevo producto turístico para 
la provincia de Alicante, que pueda ser capaz de generar experiencias únicas en el visitante, ya que la provincia de Alicante dispone de los atributos necesarios para hacer de la práctica del ciclismo un producto turístico de calidad.

Diversificar la oferta y generar marca territorial son los elementos sobre los cuales debe pivotar la generación del cicloturismo como producto turístico en la provincia de Alicante.

1. La provincia de Alicante: un espacio apto para el Desarrollo del ciclotuRISMO

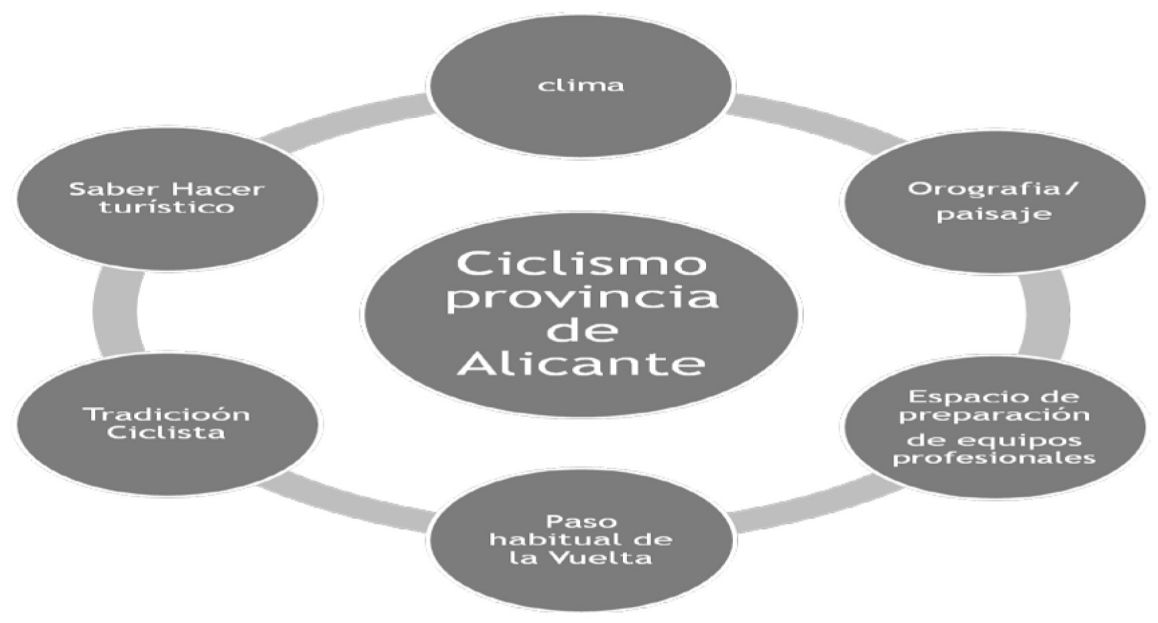

Fuente: Elaboración propia.

- Clima: Cuando hablamos de actividad turística al aire libre es necesario hacer mención al factor climático, ya que es fundamental para el buen desarrollo de la misma, y más aún en una zona como la provincia de Alicante, donde el clima ha sido fundamental para la puesta en valor y consolidación de la industria turística.

En este sentido la provincia de Alicante, disfruta de un clima especialmente benigno que posibilita la práctica de deportes al aire libre durante la práctica totalidad del año.

El factor clima por tanto posibilita desarrollar actividades turísticas vinculadas con el ciclismo en periodos del año en los que la ocupación hotelera es baja. Apostar por cicloturismo generará una nueva oferta turística en meses del año de baja ocupación hotelera.

- Paisaje/Orografía: El paisaje es la carta de presentación más personal que nos puede ofrecer un territorio, convirtiéndose en catalizador o transmisor de emociones, sensaciones y sentimientos. Por tanto el paisaje se convierte en un elemento clave para la puesta en valor y/o desarrollo de cualquier actividad turística (De San Eugenio, 2012). La demanda 
sensible a atributos relacionados con la sostenibilidad del medio ambiente, está ganando mayor peso entre los turistas internacionales, de ahí que la presentación del paisaje como elemento y/o atributo de la oferta turística vinculada con el ciclismo puede crear una imagen positiva de nuestra provincia en el turista no residente en España. El ciclismo es un deporte en el que el paisaje está muy presente como condicionante para su práctica y como estímulo para la misma (Rodriguez, 2007).

Paso habitual de la Vuelta ciclista a España: Un factor que dota de valor añadido al paisaje de la provincia de Alicante es el hecho de que es reconocido como paisaje ciclista, debido que ha sido paso habitual de la Vuelta Ciclista a España hecho que ha posibilitado una divulgación extraordinaria del mismo gracias a los medios de comunicación. Posibilitar al aficionado que practique su deporte favorito por los espacios donde ha transcurrido una de las tres mejores competiciones ciclistas a nivel mundial dota a este territorio de un valor añadido como atractivo turístico. La caravana de la vuelta ciclista a España ha transitado por un total de 18 puertos de montaña de la provincia, además de ser salida de 47 etapas y final de 44 etapas (datos Vuelta Ciclista a España).

- Espacio de preparación de equipos profesionales: en los últimos años se ha convertido en habitual, ver a ciclistas de primer nivel preparando sus temporadas en la provincia de Alicante, especialmente en la zona de la marina Alta, Marina Baixa y Comtat se han convertido en espacios muy preciados para estos ciclistas sobre todo por la tranquilidad de la carreteras, el buen estado de las mismas y la calidad climática existente en este entorno en los meses de invierno. Equipos pertenecientes a la UCI World Tour como el Astana (kazajistan), Omega-Pharma-Quik Step (Bélgica), el Team Saxo Bank (Dinamarca) o Vacansolei DMC (Holanda) son algunos ejemplos de equipos que han optado por nuestra provincia para preparar sus competiciones en los últimos años.

- Tradición ciclista: la tradición ciclista existente en la provincia de Alicante posibilita que la generación de un producto turístico vinculado con el ciclismo no sea ajeno a la realidad social de la provincia, debido a las condiciones orográficas y el estado de las carreteras, es habitual encontrar numeroso ciclistas aficionados de la provincia practicando su deporte favorito por las carreteras alicantinas habitualmente. Esta tradición ciclista se hace patente en los siguientes datos: 17 equipos ciclistas federados y 13 escuelas ciclistas federadas, a estos datos hay que sumar la gran cantidad de peñas ciclistas existentes en la práctica totalidad de los municipios de la provincia. También hay que señalar que tradicionalmente el pelotón internacional ha contado con ciclistas Alicantinos, en la actualidad podemos destacar entre otros a Rubén Plaza y a Rafa 
Valls, ambos corredores pertenecientes a la máxima categoría de ciclismo mundial la UCI World Tour.

- Saber hacer turístico: Es imposible desarrollar una actividad turística si no existen una serie de establecimientos capaces de poder absorber una demanda. En este sentido la tradición turística de la provincia de Alicante y el saber hacer de los profesionales del turismo nos posibilita poder poner en valor el cicloturismo y cualquier nueva actividad vinculada con el turismo como producto, sin necesidad de desarrollar acciones que generen gastos elevados para los empresarios del turismo. Gracias a este saber hacer en materia turística, la puesta en valor de un nuevo producto turístico, la divulgación y el consumo del mismo pueden avanzar paralelamente.

Sin la existencia de una industria turística consolidada la idea de consolidar el cicloturismo como nuevo producto turístico tendría dificultades para consolidarse. Hay que aprovechar el entorno con el objetivo de dotarlo de nuevas ofertas turísticas que posibiliten una diversificación, renovación de productos y experiencias turísticas para la provincia de Alicante.

\section{VIVIR EXPERIENCIAS COMO ATRACTIVO TURÍSTICO}

En el momento actual, en el que estamos inmersos en la etapa de declive o invierno de los modelos turísticos tradicionales, es necesario apostar por nuevas tipologías turísticas que consigan mantener la posición predominante que tiene la industria en la balanza comercial de la provincia de Alicante. Como se señala en el Plan Nacional Integral de Turismo 2012-2015 publicado por el Ministerio de Industria Energía y Turismo aquellos destinos turísticos que no tengan en cuenta esta nueva situación o no sepan adaptarse a la misma perderán progresivamente su posición dentro del mercado.

La provincia de Alicante posee los suficientes atributos sociales, económicos, paisajísticos y/o empresariales para poder afrontar esta situación, mediante la consolidación y reorganización del producto sol y playa y la apuesta por nuevos productos basados en la vivencia de experiencias por parte de los turistas. El turista del siglo XXI no se conforma con ver cosas además quiere vivir experiencias sobre el territorio (Canoves, 2013).

En el caso que nos ocupa nos dirigimos a un segmento de clientes concreto: a aquellos que practican ciclismo y viven su experiencia turística desde la bicicleta, este es un tipo de turista cada vez más común, proveniente especialmente de los Países Bajos y del mundo escandinavo; este perfil de turista es conocido como cicloturista.

Sin olvidar las posibilidades que nos ofrece la provincia de Alicante para desarrollar productos turísticos relacionados con cualquier tipo de bicicleta, 
en este caso nos fijaremos en el ciclismo de carretera. Ya que planteamos un modelo turístico basado en ofrecer al cicloturista aquellas experiencias que han vivido en la provincia de Alicante ciclistas profesionales tanto en competición como durante sus estancias de pretemporada. El cicloturista valora muy positivamente saborear las experiencias que han tenido los ciclistas profesionales.

El territorio de la Provinica de Alicante nos ofrece muchos espacios para la experiencia ciclista ya que este espacio geográfico ha sido paso habitual de la Vuelta Ciclista a España, en este sentido, hay que utilizar el valor añadido que ha generado la Vuelta ciclista a España en la percepción de la provincia como territorio ciclista, para desarrollar este modelo turístico basado en el disfrute de un territorio desde la bicicleta.

En este sentido es necesario mencionar el papel que juegan los eventos deportivos en el posicionamiento turístico de un espacio territorial. Entendiendo evento deportivo como aquellas actividades o competiciones deportivas capaces de atraer un número considerable de visitantes con el objeto de participar o asistir como espectadores. (Delpy, 2003)

Jiménez Morales (2009) señala que un evento por sí mismo representa una importante estrategia de promoción del territorio, pero además puede crear imágenes en la sociedad capaces de fijar una marca de ciudad en su conjunto.

Después de un gran evento que ha supuesto un elevado desembolso de presupuesto, hay que realizar una reflexión para utilizar las infraestructuras generadas a lo largo del tiempo (Santamaría, 2008).

El reto es mantener la imagen de la ciudad o del territorio afectado después del evento, dado que éste sólo aporta al posicionamiento de la ciudad antes y durante, después muere de manera rápida y se vuelve fugaz su recordación si no hay detrás toda una estrategia de mantenimiento, posicionamiento y recordación del territorio que fue en breves instantes, pero que quiere seguir siendo (Sancho Pérez, 2007). Hay que valorar, pues, qué grado de bondad tienen los eventos deportivos para el territorio y la sociedad donde se programan con el objetivo de generar desarrollo en lo local.
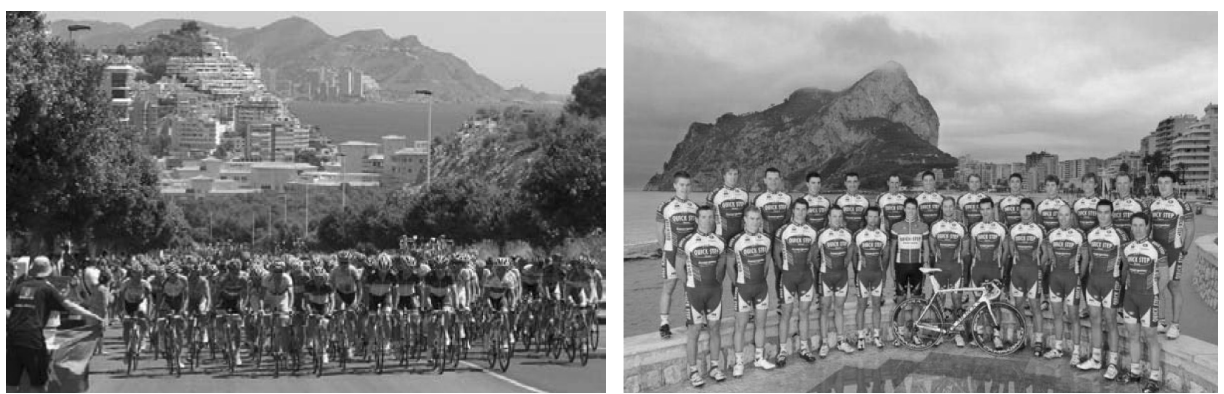

Imágenes 1 y 2: Equipos preparando la temporada. 
Este proceso de puesta en valor de un nuevo producto turístico para la provincia de Alicante pretende trabajar en ofrecer al ciclosturista las experiencias ciclistas que se han vivido en este ámbito territorial durante el paso de la Vuelta ciclista a España, evitando que el esfuerzo económico realizado por la administración pública, con el objetivo de atraer a la Vuelta Ciclista a España a la provincia, no quede diluido y visto como un mero recuerdo, sino como un elemento clave para generar en la provincia de Alicante un nuevo producto para el desarrollo local y turístico desde los principios de la gestión prudente del territorio.

Que una ruta o puerto de montaña haya sido transitado por ciclistas en competición le confiere un valor añadido muy apreciado por los cicloturistas, los cuales quieren vivir la misma experiencia puedan tener, los hermanos Schleck, Purito Rodríguez, Samuel Sánchez, Cadel Evans o Alberto Contador.

\section{GeNERAR MARCA TERRITORIAL COMO PROCESO DE PROMOCión TURÍSTICA}

El conocimiento de la identidad de un territorio, es clave para situarlo en el mapa turístico, la marca territorial es un acicate que sitúa a un espacio en el imaginario turístico (Canoves, 2013).

Para generar una marca territorio es fundamental establecer una idea, en torno a atributos emocionales. Esta idea ha de ser diferenciadora y al mismo tiempo simple y fácil de comprender. También es fundamental que sea universal, en el sentido que sea reconocible y eficaz para múltiples públicos en diferentes situaciones y versátil, dotada de contenido visual y verbal. Para un desarrollo eficaz, esta idea debe incorporar iconos culturales, paisajísticos, deportivos y/o empresariales. (Martínez, 2010).

Entendemos el concepto "marca territorial" como un proceso de trabajo que consigue identificar a un territorio teniendo en cuenta unos atributos o características que lo diferencian del resto, desde una perspectiva social, paisajística, cultural, económica etc. La marca territorial debe ir más allá de la simple representación de la marca con un logo o imagen, tiene como fin desarrollar procesos y actividades desde la óptica del desarrollo local, con el objetivo de beneficiar económica y socialmente a los espacios influenciados por la actividad.

Un territorio no puede reinventarse de cero. Parte de una realidad y de una historia que no puede obviarse o negarse. Pero sí pueden llevarse a cabo intervenciones, para conseguir la identificación del territorio con una actividad concreta; en este caso el ciclismo. La marca territorial no es un simple logo o una campaña de marketing, la marca territorial es un proceso para generar acciones que reviertan en beneficios económicos vinculados a la idea de producto de la marca, en nuestro caso el ciclismo.

La marca territorial por si sola genera promoción de destino, es fácil señalar algunos ejemplos que corroboran la importancia de la marca territorial a la 
hora de posicionar en el mercado espacios turísticos, sin necesidad de generar procesos de consumo de territorio para el desarrollo de la actividad turística. El paisaje del cerezo en el Valle del Jerte, el vino para la Rioja, el jamón para Jabugo o el Quijote para Castilla la Mancha son algunos ejemplos de marca territorial.

Para el desarrollo del cicloturismo en el provincia de Alicante, es fundamental la creación de una marca territorial que identifique a la provincia de Alicante como un territorio para el desarrollo de actividades relacionadas con el ciclismo, en este sentido, que la Vuelta Ciclista a España haya transitado con asiduidad por este espacio, dota a la provincia de un valor añadido, fruto de la repercusión que ha tenido en los aficionados las imágenes aparecidas en los medios de comunicación, relacionadas con el ciclismo y este ámbito geográfico. Los acontecimientos deportivos que invaden a diario nuestras casas por medio de Internet y televisión, constituyen uno de los más poderosos vehículos de fascinación de las multitudes (Machado Gomes, 2009), este hecho hay que aprovecharlo para generar marca territorial vinculada con el ciclismo en la provincia de Alicante.

Con esta iniciativa pretendemos proyectar una imagen coherente y positiva que ayude consolide a la provincia como territorio ciclista, mediante la mejora de la percepción por parte del público objetivo.

Hay que conseguir que el significado provincia de Alicante genere en el receptor el significante del ciclismo como actividad turística de la provincia junto con las otras tipologías turísticas existentes con peso en el mercado actual.

\section{UN PRODUCTO SIN CONSUMO TERRITORIAL}

Es necesario llevar a cabo políticas turísticas dirigidas a poner en valor los activos ambientales, culturales y paisajísticos del territorio, con el objetivo de respetar la capacidad de acogida del territorio y no incrementar la huella ecológica (Plan estratégico global de Turismo de la Comunidad Valenciana, 2010-2020).

El territorio ejerce una triple función dentro de la actividad turística: en primer lugar, es su principal argumento, el componente esencial que motiva el flujo de visitantes; en segundo lugar, es el soporte físico de la actividad; y en tercer lugar, es también un factor condicionante de esta. Por tanto, si no existe un respeto por el territorio entendido como soporte de la actividad, a medio plazo las actividades turísticas desarrolladas sobre él, perderán interés para los posibles turistas interesados en vivir experiencias en el territorio turístico.

A medio plazo, se asume una mayor concienciación ambiental de la demanda turística. Los destinos con mayor valor añadido serán aquellos donde la actividad turística se desarrolle de manera compatible con el medio ambiente y la sociedad local. 
El territorio nos ofrece las características idóneas para el desarrollo del ciclosturismo como actividad turística, el paisaje aparece como parte de la oferta, para el disfrute del cicloturista, no existe la necesidad de generar o reordenar espacios turístico-territoriales, hecho que dota a esta actividad de un valor añadido vinculado con la sostenibilidad y el no aumento de la huella ecológica vinculada con la actividad turística.

\section{UN PRODUCTO PARA EL DESARROLLO LOCAL Y TURÍSTICO}

A pesar de las adversas circunstancias económicas que están afectando al conjunto de la economía española, el turismo en la provincia de Alicante sigue siendo una actividad estratégica con gran relevancia económica y social. A pesar de estas ventajosas características hay que trabajar con el objetivo de propiciar que la industria turística no pierda ese papel de industria puntera en la generación de rentas dentro del contexto territorial provincial.

Son muchos los documentos elaborados desde la administración que apuestan por el apoyo al sector turístico con el objetivo de que no pierda el posicionamiento socio-empresarial que esta industria tiene en nuestro país y todos ellos hablan de la necesaria reconversión y asunción de nuevos productos capaces de generar un impulso para el desarrollo local: entendiendo desarrollo local como el proceso que posibilita el desarrollo social, económico, territorial y medioambiental de un territorio, desde una óptica en la que los beneficios recaigan sobre la ciudadanía

En este tiempo de incertidumbre las actividades vinculadas con el desarrollo local están cogiendo fuerza como alternativas para la generación de nuevos modelos de gestión y desarrollo territorial.

Las características del cicloturismo posibilitan que gran parte del territorio sea espacio potencial de esta actividad turística, aspecto este que favorece que muchas zonas de la provincia puedan verse beneficiadas por las presencia de ciclistas.

Los procesos de desarrollo local vinculados con el ciclismo deben basarse en los siguientes puntos de actuación estratégica.

- Creación de la marca territorial vinculada con el ciclismo.

- Creación de una red de rutas para cicloturistas

- Utilización de las tecnologías de información geográfica para dotar de valor añadido al producto

- Red de establecimientos turísticos vinculados a la marca y a la atracción de ciclistas tanto profesionales como amateurs.

- Diversificar la oferta turística en las zonas costeras y ofrecer una nueva oferta para las zonas de interior.

Trabajando con estas perspectivas estratégicas, dotaremos a la Provincia de Alicante de un nuevo producto turístico basado en el ciclismo, con el objetivo 
de posicionar nuevos y renovados productos turísticos, que continúen consolidando a la provincia como punta de lanza de la industria turística nacional desde un modelo que no consuma territorio y apostando por la sostenibilidad como valor añadido a la oferta turística.

La generación y consolidación de este nuevo producto turístico para la provincia de Alicante debe entenderse como un proceso de trabajo desde el desarrollo local que consiga identificar a un territorio teniendo en cuenta unos atributos o características que lo diferencian del resto, desde una perspectiva social, paisajística, cultural, económica.

BIBLIOGRAFÍA

CÀNOVES VALIENTE, G. (2013): Turismo de interior: retos y oportunidades. Villena patrimonio y cultura. En jornadas ETV+i Junt@s hacemos Villena. Villena 25 y 26 de abril de 2013.

DE SAN EUGENIO VELA, J. (2012): «Comunicación participativa, participación ciudadana y paisaje. Un estudio de caso: el Observatorio del Paisaje de Catalunya», Redes.com no 4, pp. 163-174.

INVAT-TUR: «Plan estratégico global de Turismo de la Comunidad Valenciana, 2010-2020».

JIMÉNEZ MORALES, M. (2009): «Identidad territorial y promoción turística: la organización de eventos como estrategia de creación, consolidación y difusión de la imagen de marca del territorio», Zer, no 26 , pp. 277-297.

MACHADO GOMES, R. (2008): «El ocio y el deporte en la época del turismo global», Apunts educación física y deportes, $\mathrm{n}^{\circ}$ 97, pp. 37-46.

MINISTERIO DE INDUSTRIA, ENERGÍA Y TURISMO «Plan Nacional Integral de Turismo 2012-2015»

RODRÍGUEZ GUTIÉRREZ, F. (2007): El ciclismo como marca territorial: El anillo ciclista de la Montaña Central de Asturias: Cecodet, pp. 281.

SANTAMARÍA, A (2008): «Análisis de resultados del turismo de eventos» Gestion de Hoteles. pp. 33-39.

SANCHO PÉREZ, A. (2007): «El Impacto de la America's Cup en la Ciudad de Valencia», www.esade.edu.com

Webs Consultadas

www.lavuelta.com

www.fccv.es 